being freely given, and it contains a number of clear and very interesting plates. It ends with a short glossary and two indexes. It is described on the cover as "the story of the fascination of gold and the attempts of chemists, mystics, and charlatans to find the Philosophers' Stone". It tells this story in a masterly way and it can be warmly recommended to specialists, who will find no faults in it ; to chemists, who will gather from it the origins of their science; and to readers with little knowledge of alchemy or chemistry, who will be both instructed and entertained. It makes clear the fascination which alchemy exerted over so many centuries, and points out the very different course of development of chemistry as compared with other sciences such as physics or biology. The book is very well produced and is very good value for money. J. R. Partington

\section{BATTISTA GRASSI: CENTENARY CELEBRATION}

Symposia Genetica Volume 4: in Onore di Battista Grassi nel Centenario della sua Nascita

Pp. $x+511$. (Pavia: Tipografia del Libro-Soc. A.R.L., 1956.) 8500 lire ; 13.50 dollars.

$\mathrm{T}$ HE celebration of the centenary of Battista Grassi's birth in Symposia Genetica is an indication of the broad conception of the functions of this publication. Indeed, the editorial preface concludes with the announcement of a change in its title to "Symposia Genetica et biologica italica". Grassi himself, who never worked upon problems of genetics, is regarded as having fathered a movement towards the synthesis of studies of embryology, parasitology, ecology and taxonomy in relation to a cors of heredity.

An interesting description of the organization and aims of the Centro Apennino, with emphasis upon the Battista Grassi Laboratory of micro-bio-parasitology, is followed by a somewhat uneritical, but none the less important, biography entitled "Onoranze a Battista Grassi", including a complete bibliography of his publications.between 1874 and 1900. The later works, on the transmission of malaria, are omitted, having been reserved for separate consideration at some later date. There follow some sixty pages which belong to the more spacious days when publishers could light-heartedly disregard limitations of space. It seems unlikely that even a passing interest may reside in the hundreds of congratulatory messages of the world's universities and academic societies, and their omission would have reduced considerably the formidable price of the book and detracted in no sense from its value.

Nearly half the work consists of an extraordinary variety of letters of appointment to and acceptance of various posts, of recommendation to promotion, tendering honours from academic societies, letters from his students to their master and finally exchanges of zoological comment from his contemporaries throughout Europe. The latter provide much interesting comment upon the state of the science and upon the honour and respect in which Grassi was held. It is unfortunate, however, that they have not been more adequately edited. Having been set up from manuscript in half a dozen languages, they contain many glaring errors which should have been corrected by someone familiar with both the language of the correspondent and the personalities to whom they have referred. Moreover, Grassi, as is well known, was protagonist in more than one acrimonious dispute, and it is regrettable that the free personal criticisms which several correspondents allowed themselves in private letters should be sub. jected now to the light of publication.

There follow the memoirs contributed by the Russian delegation which arrived too late for the celebrations at Como, the papers in consequence being delivered later in 1954 at the Istituto Spallanzani of the University of Pavia. Briefly, these comprise two summary reviews of the state of helminthology and agricultural microbiology respectively in the U.S.S.R. and six original papers on diverse subjects. The later inclusion of a hitherto unpublished letter dated November 29, 1780, from Spallanzani to Gemello Villa is of some historical interest, but does not appear to be closely relevant to the theme of the work.

L. A. Harvey

\section{CHEMICAL ACTIVITIES OF THE PROTOZOA}

\section{Biochemistry and Physiology of Protozoa}

Edited by S. H. Hutner and André Lwoff. Vol. 2. Pp. xiii +-388. (Now York: Academic Press, Inc.; London : Academic Books, Ltd., 1955.) 9 dollars. URING the four years which have elapsed since
the appearance of the first volume of this publication (reviewed in Nature, 169,895 ; 1952) considerable advances have been made in our knowledge of the biochemistry and physiology of the Protozoa.

These are reflected in the contributions to the second volume, which is introduced by s. H. Hutner, who gives a general review of recent achievements in this field and of problems still in need of elucidation, with special reference to the role of Protozoa as tools in comparative biochemistry and phylogeny. The second chapter, by S. H. Hutner and $\mathrm{I}_{\text {. }}$ Provasoli, deals with the comparative biochemistry of various Phytomonadine and Zoomonadine flagellates. Among the questions discussed are the algal origins of phagotrophic species, the nutrition of certain phytoflagellates, the cultural requirements of 'Trypanosomidae, the metabolic activities of 'Trichomonads, and the physiology of vitamin $B_{12}$ in flagellates. In the third chapter, S. A. Barker and E. J. Bourne deal with the composition and synthesis of starch in the colourless flagellate, Polytomella. The next two chapters, by W. J. van Wagtendonk, are devoted to the nutrition of ciliates, and to the role of metabolites in encystation and excystation of Protozos. In the following chapter, G. R. Seaman provides a detailed account of the metabolism of free-living ciliates. In the seventh chapter, R. E. Hungate discusses nutrition and metabolism in the symbiotic ciliates and flagellates of ruminants and insects (termites and cockroaches), respectively, in the light of their relationship to the corresponding hosts. A chapter by $M$. Sussman is devoted to the physiology of amoeboid slime moulds (Myxomycophita Acrasiales or Mycetozoa) at different stages of their life-cycle. This is followed by a chapter, by L. G. Goodwin and I. M. Rollo, devoted to the chemotherapy (especially with newer drugs) of malaria, piroplasmosis, trypano. somiasis and leishmaniasis, special consideration being given to the correlation between chemothera- 